\title{
BASES FLORÍSTICAS PARA CONSTRUÇÃO DE TRILHA INTERPRETATIVA E PROGRAMAS DE EDUCAÇÃO AMBIENTAL NA EMPRESA RADIO HOTEL (SERRA NEGRA, SP)
}

Steve de Oliveira Costa ${ }^{1}$

Resumo: Nesse trabalho teve-se como objetivo a construção de uma trilha de interpretação ambiental, a partir da caracterização florística do componente vegetal lenhoso, ocorrente em uma área de remanescente florestal localizada na empresa Radio Hotel Resort \& Convention, Serra Negra - SP. Nessa trilha, os visitantes tem a oportunidade de caminhar juntamente com um guia e/ou mesmo desenvolver uma caminhada ao longo da citada trilha de forma auto-guiada, por um percurso com espécies botânicas plaqueadas, contendo informações acerca da importância ecológica, econômica e/ou socioambiental de tais espécies, obtidas através de consulta a literatura específica. A identificação do material botânico coletado foi realizada por meio do uso de bibliografia específica, comparação com exsicatas depositadas no herbário ESA, da Universidade de São Paulo, e consulta a especialistas. $O$ presente trabalho visou ainda à divulgação desta proposta, isto é, o incentivo de outras empresas hoteleiras para a construção de trilhas interpretativas, tornando assim esta proposta uma oportunidade de agregar práticas educativas ambientais a estas empresas, bem como de ampliar suas opções de lazer.

Palavras-chave: Composição Florística; Educação Ambiental; Biodiversidade.

\footnotetext{
${ }^{1}$ Instituto de Biologia, Universidade Estadual de Campinas, SP. E-mail: steve.costa.soc@gmail.com
} 


\section{Introdução}

As áreas verdes municipais abrigam importante diversidade biológica, sendo constituídas por espaços verdes essenciais de lazer, de conservação ambiental e detém grande potencial para o desenvolvimento de atividades educativas, sendo representadas pelas próprias ruas arborizadas, praças, parques e remanescentes florestais. Estas áreas, muitas vezes, apresentam remanescentes da vegetação regional e assim desempenham um papel vital para a conservação e restauração da biodiversidade regional e, consequentemente, para a melhoria das condições ambientais das populações que ali habitam (FIGUEIREDO; MATTIAZZI; KLEFFASZ, 2007).

As áreas de Floresta Estacional Semidecidual, principal tipo de vegetação encontrada no município de Serra Negra - SP, devido à alta fertilidade do solo, sofreram, e ainda sofrem, grandes pressões antrópicas em favor do desenvolvimento da agricultura cafeeira e expansão de centros urbanos (KRONKA et al., 2005).

De acordo com Soares (1998), áreas verdes municipais, tais como remanescentes florestais, parques e jardins públicos desempenham, nos centros urbanos, além de seu papel de zonas verdes, outros papéis de alta relevância, pois são obras de arte com grande valor paisagístico e ambiental que tem como finalidade o incentivo à disseminação dos sentimentos de coletividade.

Atualmente, a prática de atividades ao ar livre e a interação do homem com o ambiente natural é algo cada vez mais restrito e incomum. Nesse cenário, as trilhas interpretativas têm sido difundidas como instrumento de Educação Ambiental, especialmente em áreas naturais e de significado histórico, de modo a permitirem aliar o aprendizado ao lazer de seus visitantes (TUAN, 1980).

As trilhas interpretativas constituem-se na trajetória de caminhos dotados de significados geográficos, históricos, culturais e/ou ecológicos e, quando bem planejadas, são significadas pela interpretação ambiental (VASCONCELLOS, 2006), que possibilita revelar aos visitantes os significados e as relações existentes no ambiente por meio de seus próprios sentidos (TILDEN, 2007).

As trilhas interpretativas, quando realizadas em áreas verdes, agregam as espécies botânicas ocorrentes na área ao seu percurso, e ampliam assim o potencial de aprendizado em seu percurso, visto que a flora arbustivo-arbórea tem características com grande potencial educativo. Assim, quando no planejamento de uma trilha interpretativa, esta biodiversidade vegetal deve ser considerada como um dos elementos-chave e deve ser conhecida previamente. Uma grande parcela dos recursos e do tempo do planejador da trilha a ser constituída devem ser empregados para o conhecimento do componente arbóreo-arbustivo, pois estas espécies darão suporte à práticas de interpretação ambiental (SILVA; LORENCINI JÚNIOR, 2010).

A implantação de trilhas interpretativas visa ainda fornecer subsídios para a conservação e restauração da biodiversidade, contribuindo assim para a formação de uma consciência ambiental nos visitantes acerca da importância de 
se preservar a biodiversidade regional, particularmente, em uma paisagem extremamente antropizada como é a encontrada na região de Serra Negra - SP (KRONKA et al., 2005).

No percurso de uma trilha interpretativa guiada, as informações são transmitidas por um intérprete, cuja principal função é desenvolver uma relação afetiva entre os visitantes e o meio ambiente (GUIMARÃES; MENEZES, 2006).

As trilhas de interpretação ambiental constituem-se em uma prática pedagógica dinâmica, que proporciona aos seus visitantes uma oportunidade de aproximação com a realidade dos temas abordados. Essas trilhas suscitam entre seus frequentadores uma dinâmica de observação, reflexão e de sensibilização, que os coloca em um caminho de autoconhecimento acerca da importância da diversidade biológica ali presente e de seu papel para a conservação e restauração de um espaço ao qual eles têm acesso, bem como uma visão crítica acerca do meio em que vivem e atuam (BARCELOS, 2005; GUIMARÃES; MENEZES, 2006; LOUREIRO, 2009; GAMBOA; BARRETTO; XAVIER, 2009).

A implantação de trilhas interpretativas visa expandir o contato do homem com a natureza para estimular, guia e demais visitantes, à construção de uma sociedade ecologicamente prudente, socialmente justa, politicamente atuante e economicamente viável, que contribua efetivamente para o enfrentamento da grave crise socioambiental da atualidade (LOUREIRO, 2009; GAMBOA; BARRETTO; XAVIER, 2009).

O aspecto central que motivou o presente trabalho está diretamente relacionado à possibilidade de construção de uma trilha interpretativa guiada, a partir da caracterização da composição florística da flora arbustivo-arbórea ocorrente na área, bem como para o incentivo da criação de atividades e programas de Educação Ambiental no município de Serra Negra - SP. Desse modo, a partir da construção de uma trilha interpretativa guiada, têm-se como preocupação propiciar atividades que revelem os significados e as características do ambiente. A trilha interpretativa guiada proposta poderá assim ser um instrumento de grande relevância a programas de Educação Ambiental ao ar livre (PÁDUA, 1997; POSSAS, 1999; TILDEN, 2007).

\section{Material e métodos}

\section{Caracterização da área de estudo}

\section{Aspectos geográficos, físicos e biológicos}

A área de estudo abrange o município de Serra Negra (SP), localizado no nordeste do Estado de São Paulo, entre as coordenadas $22^{\circ} 21 \mathrm{~m}$, de latitude Sul e 46을 $25 \mathrm{~m}$, de longitude Oeste. Segundo o sistema de classificação proposto por Köppen, a região de Serra Negra apresenta o clima do tipo Cwa, subtropical de inverno seco, com verões quentes e úmidos e invernos secos, cuja 
temperatura média anual fica entre $13,3^{\circ}$ e $25,6^{\circ} \mathrm{C}$ e a pluviosidade média é inferior a $1.500 \mathrm{~mm} /$ ano (KÖPPEN, 1948; CEPAGRI, 2014).

O relevo regional é, predominantemente, montanhoso e acidentado. A região situa-se na Depressão Periférica Paulista e a altitude média do município de Serra Negra é de 920 m (ESPÍNDOLA; GARCÍA, 1978).

A maior parte da região insere-se no contexto hidrográfico da Bacia do Paraná e na Unidade de Gerenciamento dos Recursos Hídricos do rio MogiGuaçu (KRONKA et al., 2005). Como se encontra inserida em uma paisagem extremamente antropizada, em uma matriz principalmente cafeeira, a vegetação da região de Serra Negra encontra-se, atualmente, bastante fragmentada e restrita a pequenos fragmentos florestais (Figura 1).

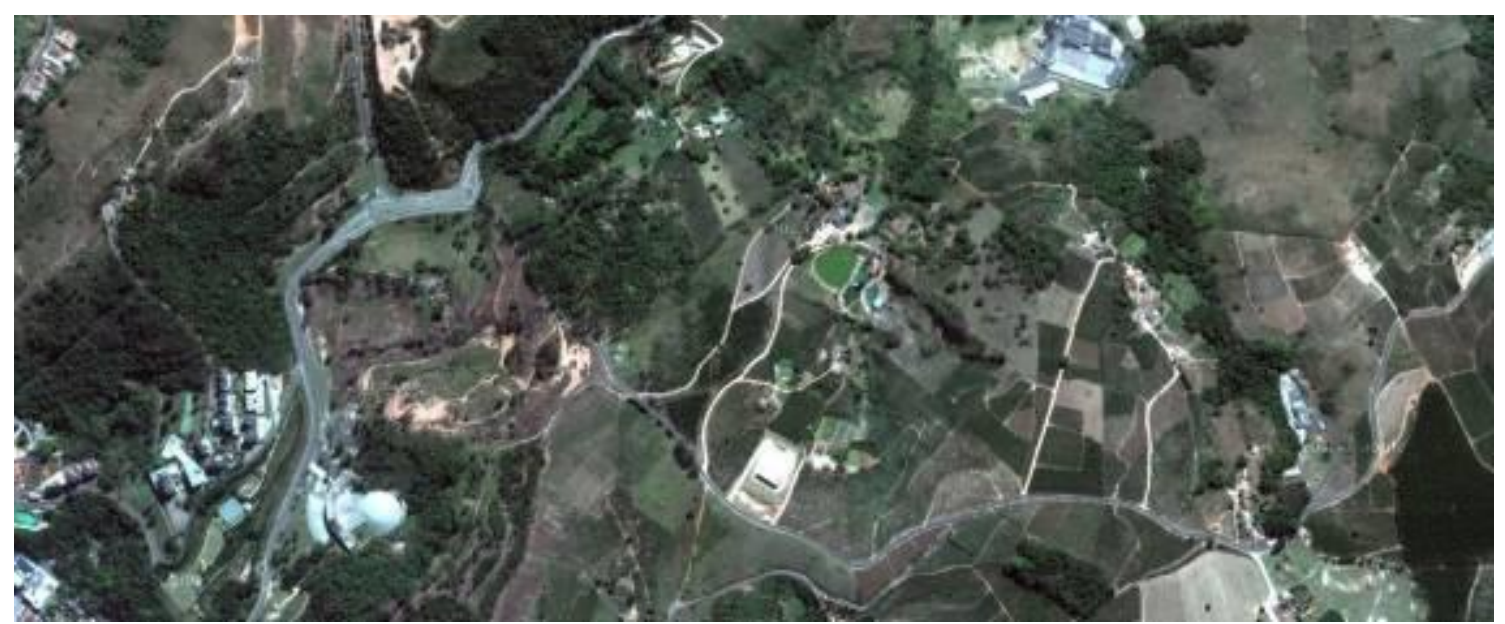

Figura 1: Fragmentos florestais localizados no município de Serra Negra evidenciando a extrema fragmentação da sua vegetação original. Fonte: GOOGLE MAPS (2015).

Segundo Veloso, Rangel Filho e Lima (1991), o principal tipo vegetacional encontrado na região é a Floresta Estacional Semidecidual. De acordo com Ramos et al. (2008) esse tipo de vegetação apresenta dossel irregular, localizado entre 15 e $20 \mathrm{~m}$ de altura, com a presença de árvores emergentes de até $30 \mathrm{~m}$ de altura.

Seu conceito ecológico está condicionado à dupla estacionalidade climática, uma tropical, com época intensa de chuvas de verão seguida por estiagem acentuada e outra subtropical (VELOSO, 1992).

\section{O empreendimento hoteleiro Radio Hotel}

A empresa Radio Hotel foi criada em 1945, no município de Serra Negra, uma Estância Hidromineral do Estado de São Paulo. Entre os principais setores da atividade econômica do município estão o turismo, a agricultura e a pecuária. Este empreendimento hoteleiro, localizado em uma área central do município, abrange $60.000 \mathrm{~m}^{2}$, e entre suas atrações destacam-se a área de remanescente 
florestal, com cachoeiras e mata de "araucárias" (Araucaria angustifolia (Bertol) Kuntze) (Figura 2), espécie ameaçada de extinção (IUCN, 2014a). O Radio Hotel além de receber hóspedes de diferentes regiões do Brasil, ainda recebe, eventualmente, hóspedes de outros países.

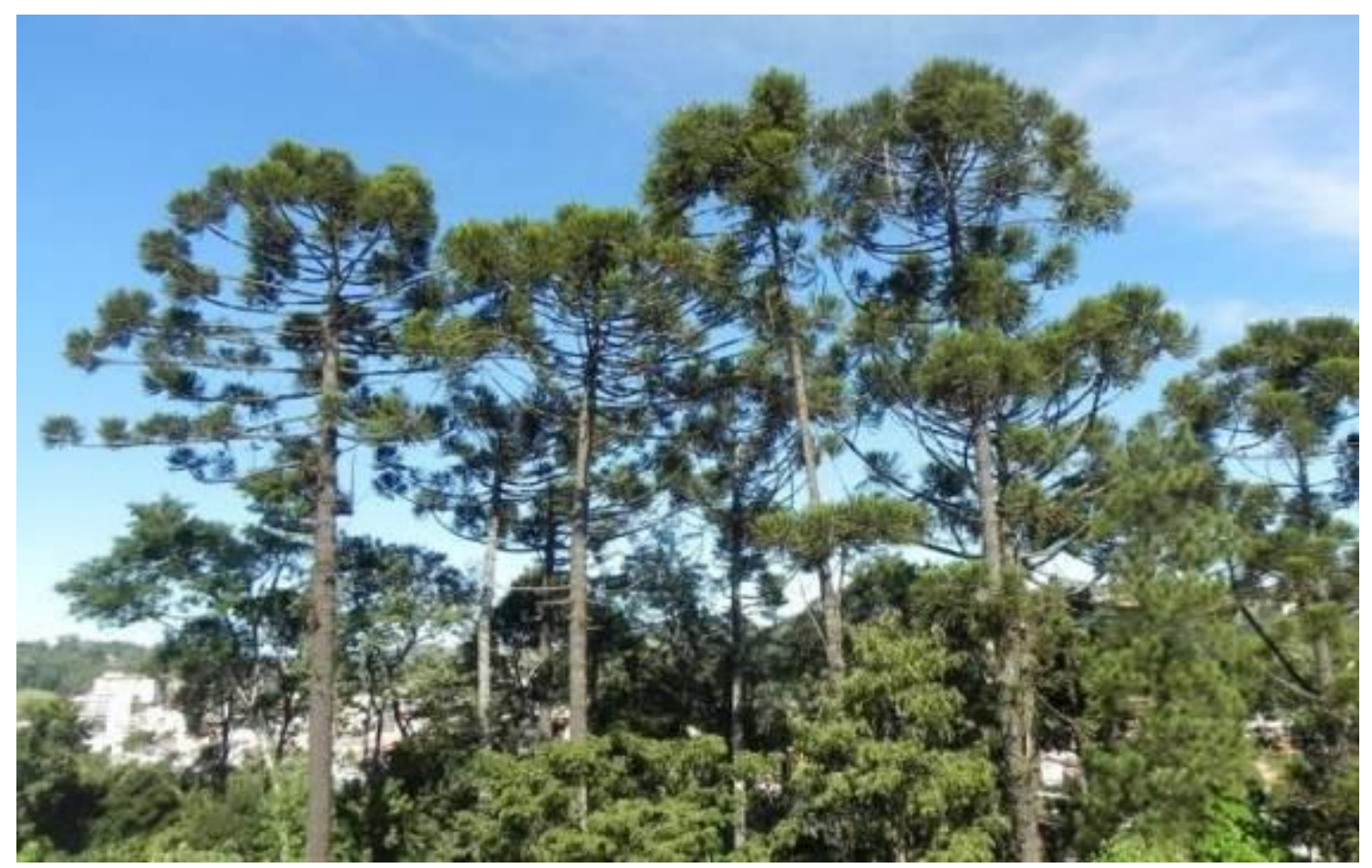

Figura 2: Indivíduos da espécie "pinheiro-do-paraná", localizados em um remanescente florestal no interior do Radio Hotel, Serra Negra (SP).

De acordo com os dados mencionados anteriormente, percebe-se o potencial que o empreendimento hoteleiro Radio Hotel detém para a implantação de uma trilha interpretativa e elaboração de atividades e Programas de Educação Ambiental, tendo em vista a ampliação do papel educador ambiental desta empresa e, consequentemente, de potencializar o seu papel de conservação e restauração de biodiversidade regional.

\section{Desenho Experimental}

O empreendimento hoteleiro Radio Hotel foi selecionado como área de grande importância e relevância para a implantação de uma trilha interpretativa, pois além de ser abrigo de importante diversidade biológica, cultural e histórica do município de Serra Negra (SP), ainda se trata de um amplo complexo hoteleiro, de grande importância socioambiental nesta região.

A escolha do empreendimento Radio Hotel como local para a implantação de uma trilha interpretativa visou também desenvolver uma maior aproximação e 
articulação de práticas e políticas socioambientais com esta empresa e possibilitar o acesso a tais práticas por seus hóspedes, oriundos de diferentes regiões brasileiras, bem como de diferentes países.

Os indivíduos da comunidade vegetal lenhosa, quando presentes e selecionados como objetos de interpretação ambiental no percurso e entorno da trilha, foram coletados partes de seu material botânico e identificados ao nível taxonômico de espécie.

As coletas de material botânico foram realizadas com tesoura de alta poda acoplada em cabo de alumínio e tesoura manual. Estes materiais foram demarcados com fita adesiva e acondicionados em sacos plásticos para posterior prensagem, secagem e identificação, conforme recomendações de Fidalgo e Bononi (1989). Todo o material botânico coletado foi identificado utilizando-se bibliografia específica, consulta a especialistas e comparação com material depositado no herbário ESA, da Escola Superior de Agricultura "Luiz de Queiroz" da Universidade de São Paulo (ESALQ-USP), Piracicaba - SP. Foi também desenvolvido um levantamento fotográfico para registro das espécies botânicas identificadas, visto que algumas se tratam de espécies cultivadas em jardins paisagísticos ou pomares, localizados no entorno do remanescente florestal, estas não foram incorporadas ao herbário ESA.

$\mathrm{Na}$ construção da trilha interpretativa alguns critérios, propostos por Vasconcellos (1998), foram considerados para a seleção do local de implantação, tais como a seleção de áreas que apresentavam características naturais comuns, permitindo assim interpretações semelhantes, e áreas que não apresentavam placas interpretativas anteriores a este trabalho, bem como não fossem muito extensas e com baixo a médio grau de dificuldade de acesso, pois apesar de áreas de difícil acesso, geralmente, guardarem ambientes melhor preservados, evitou-se a exposição dos visitantes a riscos, e esse fator pesou assim na escolha dos locais dentro da área de estudo.

A trilha interpretativa proposta foi do tipo guiada, isto é, conta com a presença de um monitor intérprete que, segundo Moraes (2000), é aquele que além de conduzir o grupo pelo percurso estabelecido também estimula a sua participação nas atividades através das sensações, experiências e questionamentos a respeito do tema proposto. Esse tipo de trilha possui como vantagens a diminuição do risco de destruição ambiental, o esclarecimento de possíveis dúvidas e uma maior segurança para os visitantes, além de poder também ser adaptada a participantes de diferentes idades, nível de escolaridade, etc. Também constituiu uma vantagem o fato das pessoas terem de seguir o ritmo do grupo e realizar as visitas em horários pré-determinados por meio, por exemplo, de agendamento com o guia.

O plaqueamento das espécies botânicas ao longo da trilha, permite ainda o seu percurso de forma autoguiada. No entanto, de forma guiada é possível ampliar o potencial de observação dos visitantes por meio das informações disponibilizadas pelo guia, que adicionam a visualização de novos elementos em 
sua trajetória, como por exemplo, a inserção no percurso de novas informações sobre os seus elementos de interpretação ambiental.

A trilha interpretativa foi organizada com a finalidade de apoiar a inserção de Programas de Educação Ambiental nesta empresa, fornecendo subsídios para a formação de uma consciência socioambiental entre os seus hóspedes, bem como para o incentivo da inserção de estratégias e ações para auxiliar na conservação e restauração da biodiversidade regional.

Primeiramente foram selecionadas as espécies botânicas como objeto de interpretação ambiental, distribuídas aleatoriamente ao longo da trilha. O padrão para a seleção das espécies botânicas foi realizado a partir das características de destaque de cada espécie, procurando-se selecionar aquelas de maior importância (ecológica, econômica, socioambiental, etc) e fácil percepção ao longo do caminho percorrido.

\section{Resultados e discussão}

\section{Escolha e identificação dos espécimes arbustivo-arbóreos explorados durante o percurso da trilha interpretativa}

No exercício de observação e estudo dos recursos naturais e culturais presentes no Radio Hotel, foi possível identificar, em uma observação preliminar da área, pontos de alta relevância e estratégicos para a proposição de ações de Educação Ambiental.

Entre estes pontos observados, pode-se ressaltar a presença de indivíduos arbóreos adultos e regenerantes de "cedro" (Cedrela fissilis Vell. Meliaceae) e de folhas em seu entorno da espécie "araucária" (Araucaria angustifolia (Bertol) Kuntze - Araucariaceae) (Figura 3), ambas atualmente ameaçadas de extinção, devido a sua intensa exploração madeireira. Esses aspectos podem ser explorados durante o percurso da trilha, ressaltando-se também aos visitantes a importância da conservação e restauração desta área de vegetação remanescente, haja vista a ocorrência de espécies ameaçadas de extinção (IUCN, 2014a; IUCN, 2014b). 


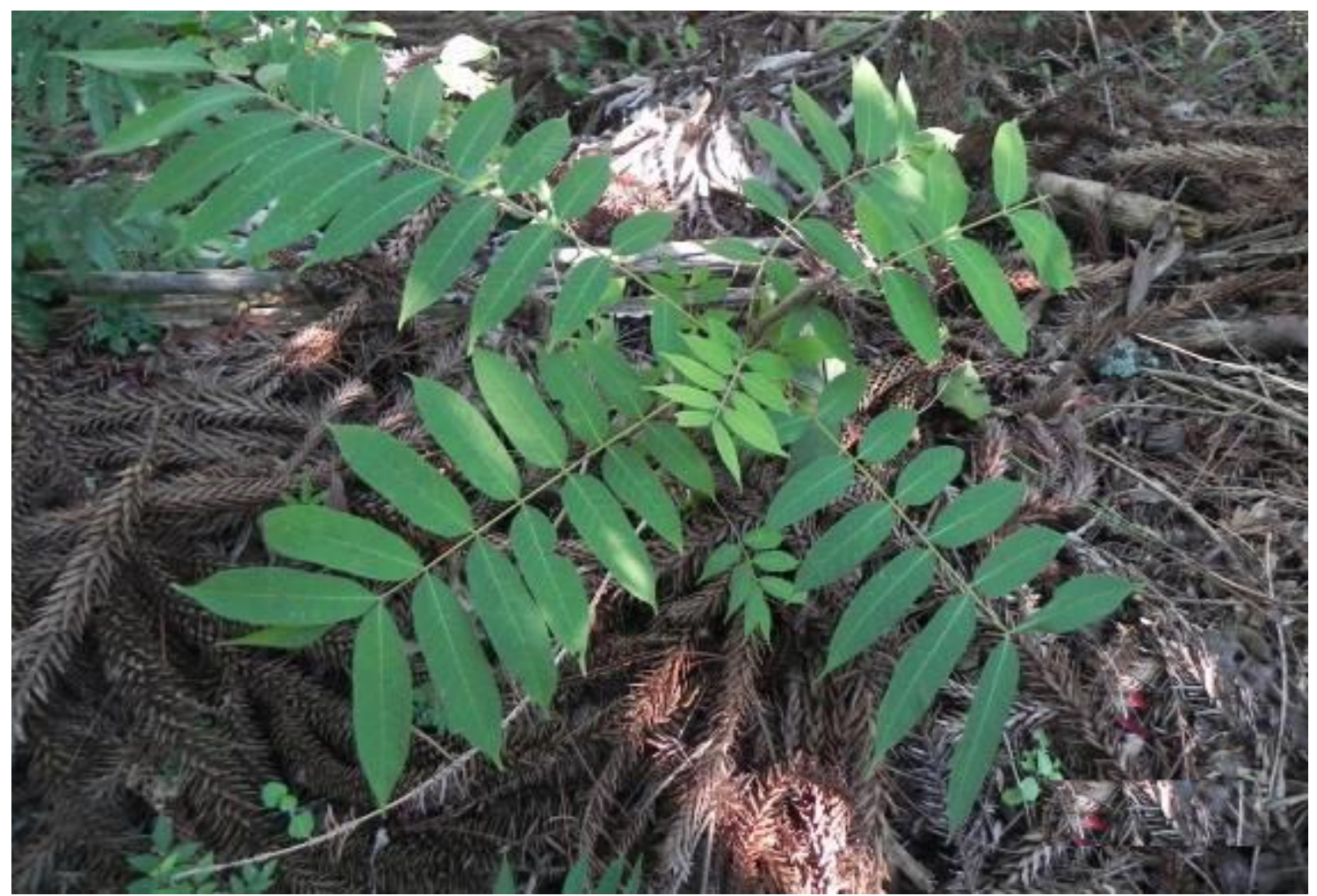

Figura 3: Indivíduo da espécie ameaçada de extinção "cedro" e folhas da espécie ameaçada de extinção "araucária", evidenciando a importância da conservação do remanescente florestal do Radio Hotel, Serra Negra (SP).

O Radio Hotel Resort \& Convention também abriga um curso d'água que abastece um rio na área, local de beleza cênica e abrigo da biodiversidade regional. Este local apresenta espécies arbóreas de grande porte, sendo algumas destas centenárias, que atuam como local de descanso, abrigo e reprodução para a avifauna ali presente, tais como a "paineira", conhecida como a árvore do algodão (Ceiba speciosa A. St. Hil. - Bignoniaceae).

É notável o predomínio de espécies arbustivo-arbóreas ocorrentes nesta área de remanescente florestal, que além de servirem de abrigo e fornecerem alimento para a fauna ali presente, ainda estão localizadas próximas aos locais de importância cultural e histórica no interior do Radio Hotel Resort \& Convention, tais como próximas as primeiras caixas d’água do hotel e também sendo o único percurso que permite o acesso, percorrendo a área da propriedade interna do hotel, entre a área construída para hospedagem e a área em que são oferecidas atividades de esportes e opções de lazer. Assim, estas espécies botânicas foram objeto de estudo, por agregarem alto valor a interpretação ambiental no percurso da trilha.

Deste modo, todos os espécimes arbustivo-arbóreos, quando selecionados como objeto de interpretação ambiental na trajetória da trilha interpretativa, foram coletados o seu material botânico e identificado até o nível taxonômico de espécie. Na Tabela 1 estão listadas as espécies selecionadas 
como objeto de interpretação ambiental, ocorrentes nas proximidades do percurso da trilha interpretativa implantada no Radio Hotel Resort \& Convention.

Tabela 1: Lista de espécies selecionadas como objeto de interpretação ambiental no percurso da trilha interpretativa implantada no Radio Hotel (SP).

\begin{tabular}{|c|c|c|}
\hline Família / Espécie & Nome popular & Origem \\
\hline ANACARDIACEAE & & \\
\hline Mangifera indica $\mathrm{L}$. & Mangueira & Exótica \\
\hline $\begin{array}{l}\text { ARAUCARIACEAE } \\
\text { Araucaria angustifolia (Rertol) Kuntze }\end{array}$ & & \\
\hline $\begin{array}{l}\text { Araucaria angustifolia (Bertol). Kuntze } \\
\text { ARECACEAE }\end{array}$ & Araucária & Nativa \\
\hline $\begin{array}{l}\text { Caryota urens L. } \\
\text { ASPHODELACEAE }\end{array}$ & Rabo de peixe & Exótica \\
\hline $\begin{array}{l}\text { Aloe vera (L.) Burm. F. } \\
\text { BIGNONIACEAE }\end{array}$ & Babosa & Exótica \\
\hline $\begin{array}{l}\text { Ceiba speciosa A. St. Hil. } \\
\text { FABACEAE }\end{array}$ & Paineira & Nativa \\
\hline Hymenaea courbaril L. & Jatobá & Nativa \\
\hline Piptadenia gonoacantha (Mart.) J.F. Macbr. & Pau-jacaré & Nativa \\
\hline $\begin{array}{l}\text { Schizolobium parahyba (Vell.) S. F. Blake } \\
\text { LECYTHIDACEAE }\end{array}$ & Guapuruvu & Nativa \\
\hline $\begin{array}{l}\text { Cariniana estrellensis (Raddi) Kuntze } \\
\text { MELIACEAE }\end{array}$ & Jequitibá-branco & Nativa \\
\hline $\begin{array}{l}\text { Cedrela fissilis Vell. } \\
\text { MORACEAE }\end{array}$ & Cedro & Nativa \\
\hline $\begin{array}{l}\text { Ficus benjamina L. } \\
\text { MYRTACEAE }\end{array}$ & Figueira-benjamina & Exótica \\
\hline $\begin{array}{l}\text { Myrciaria cauliflora DC. Berg. } \\
\text { PIPERACEAE }\end{array}$ & Jaboticaba & Nativa \\
\hline $\begin{array}{l}\text { Piper amalago L. } \\
\text { URTICACEAE }\end{array}$ & Falso-jaborandi & Nativa \\
\hline Urera baccifera (L.) Gaudich & Urtiga & Nativa \\
\hline
\end{tabular}

\section{Informações selecionadas e propostas na visitação a trilha interpretativa}

A partir do levantamento da composição florística das espécies selecionadas como de maior importância ecológica, econômica e/ou socioambiental na trajetória da trilha, sendo estas constituídas como elementoschave da interpretação ambiental, foram selecionadas informações acerca de suas principais características, tais como sua utilização pelo homem, importância ecológica e sua origem. Assim, por meio de consulta a informações disponibilizadas em literatura específica (e.g. LORENZI, 2008; SOUZA; LORENZI, 2008; RAMOS et al., 2008), foram levantadas as informações mais pertinentes para interpretação ambiental das 14 espécies botânicas selecionadas e identificadas ao longo da trilha. 
A partir dessas informações foram confeccionadas placas informativas para as espécies botânicas ocorrentes ao longo da trilha como, por exemplo, a placa do "pinheiro-do-paraná" (Figura 4), árvore de grande importância biológica na área de estudo, devido ao seu grande porte e exuberância, assim como devido ao seu elevado grau de ameaça de extinção, sendo esta a precursora do nome dado à trilha interpretativa do Radio Hotel, no caso, "Trilha das Araucárias".

Em cada placa interpretativa constam o respectivo nome popular, nome científico e família botânica de cada espécie, assim como informações ecológicas, econômicas e/ou socioambientais acerca de sua importância, com o objetivo de reforçar o processo educativo ambiental em relação à importância da conservação da biodiversidade regional e do papel da humanidade neste processo.

\section{"TRILHA DAS ARAUCÁRIAS"}

\section{PINHEIRO=-DO-PARANA}

Espécie: Araucaria angustifolia (Bertol.) Kuntze Família: ARAUCARIACEAE

Nomes comuns: pinho, pinheiro-brasileiro, curi.

\section{INFORMAÇÕES:}

Nativo das regiões sul e sudeste do Brasil. Já foi muito utilizada para exploração da madeira, mas em função da exploração irracional, foi quase extinta, estando hoje sua exploração controlada pelo IBAMA. A ave gralha-azul, ao esconder as sementes no solo para posterior consumo acaba, involuntariamente, plantando-a.

Figura 4: Exemplo de placa interpretativa confeccionada para a "Trilha das Araucárias", do remanescente florestal do Radio Hotel, Serra Negra (SP).

As informações mais relevantes sobre as espécies botânicas, selecionadas ao longo da trilha como objeto de interpretação ambiental e que constam nas placas interpretativas, são apresentadas na Tabela 2. 
Tabela 2: Informações ecológicas, econômicas e/ou socioambientais acerca das espécies botânicas selecionadas no percurso da Trilha das Araucárias.

\begin{tabular}{|c|c|}
\hline ESPÉCIE & INFORMAÇÕES RELEVANTES \\
\hline $\begin{array}{l}\text { 1. Mangifera } \\
\text { indica } \\
\text { (mangueira) }\end{array}$ & $\begin{array}{l}\text { Espécie que, apesar de sua origem asiática, seus frutos têm grande importância ecológica } \\
\text { como recurso alimentar para a fauna nativa, assim como grande importância econômica } \\
\text { nacional. }\end{array}$ \\
\hline $\begin{array}{l}\text { 2. Araucaria } \\
\text { angustifolia } \\
\text { (araucária) }\end{array}$ & $\begin{array}{l}\text { Nativa das regiões sul e sudeste do Brasil. Já foi muito utilizada para exploração da } \\
\text { madeira, mas em função da exploração irracional, foi quase extinta, estando hoje sua } \\
\text { exploração controlada pelo IBAMA. A ave gralha-azul, ao esconder suas sementes no } \\
\text { solo para posterior consumo acaba, involuntariamente, plantando-a. }\end{array}$ \\
\hline $\begin{array}{l}\text { 3. Caryota urens } \\
\text { (rabo-de-peixe) }\end{array}$ & $\begin{array}{l}\text { Palmeira com folhas que fornecem fibras para a confecção de cordas, pincéis, cestos e } \\
\text { outros artigos. Floresce, pela primeira vez, com cerca de } 13 \text { anos de idade. Suas folhas } \\
\text { atingem até } 5 \text { metros de comprimento, com margem serreada no ápice, semelhantes a um } \\
\text { rabo de peixe (fishtail palm). }\end{array}$ \\
\hline $\begin{array}{l}\text { 4. Aloe vera } \\
\text { (babosa) }\end{array}$ & $\begin{array}{l}\text { Planta de grande importância na indústria farmacêutica, utilizada para a confecção de } \\
\text { produtos cosméticos, devido as propriedades de suas folhas. Esta planta apresenta folhas } \\
\text { com disposição espiralada, semelhante as folhas do abacaxi. }\end{array}$ \\
\hline $\begin{array}{l}\text { 5. Cariniana } \\
\text { estrellensis } \\
\text { (jequitibá) }\end{array}$ & $\begin{array}{l}\text { Espécie de grande porte e exuberância, suas sementes são aladas, assim, quando o fruto } \\
\text { se abre, elas são dispersas pelo vento, e encontradas planando no interior desta área } \\
\text { florestal. Atualmente ameaçada de extinção, fato que evidencia a importância da } \\
\text { conservação desta área remanescente florestal. }\end{array}$ \\
\hline $\begin{array}{l}\text { 6. Ceiba } \\
\text { speciosa } \\
\text { (paineira) }\end{array}$ & $\begin{array}{l}\text { Árvore de até } 30 \text { metros de altura, com engrossamento do caule próximo a base. } \\
\text { Apresenta flores róseas solitárias e frutos com sementes envoltas por pêlos brancos } \\
\text { (algodão), que servem para encher colchões, travesseiros e almofadas. }\end{array}$ \\
\hline $\begin{array}{l}\text { 7. Hymenaea } \\
\text { courbaril } \\
\text { (jatobá) }\end{array}$ & $\begin{array}{l}\text { Madeira de coloração vermelha-escura, altamente resistente ao apodrecimento. Uso de } \\
\text { sua madeira comum na confecção de móveis e na construção civil, com fruto legume, com } \\
3 \text { a } 8 \text { sementes envoltas numa polpa amarela comestível, com odor forte. Árvore } \\
\text { importante em reflorestamentos heterogêneos. }\end{array}$ \\
\hline $\begin{array}{l}\text { 8.Piptadenia } \\
\text { gonoacantha } \\
\text { (pau-jacaré) }\end{array}$ & $\begin{array}{l}\text { Espécie comum nas florestas estacionais semidecíduas no sul e sudeste do Brasil. Árvore } \\
\text { de } 8 \text { a } 20 \mathrm{~m} \text {, com um tronco característico com placas quadrangulares, semelhantes as } \\
\text { escamas do jacaré. Na época de floração é muito procurada por abelhas e utilizada na } \\
\text { recuperação de áreas degradadas. }\end{array}$ \\
\hline $\begin{array}{l}\text { 9.Schizolobium } \\
\text { parahyba } \\
\text { (guapuruvu) }\end{array}$ & $\begin{array}{l}\text { Espécie que vive em associação com formigas, com caule oco que serve de abrigo para o } \\
\text { formigueiro, além de fornecer alimento as formigas a partir da produção de uma } \\
\text { substância em seu caule. Já as formigas protegem esta espécie do ataque de animais } \\
\text { herbívoros, tais como lagartas. }\end{array}$ \\
\hline $\begin{array}{c}\text { 10. Cedrela } \\
\text { fissilis (cedro) }\end{array}$ & $\begin{array}{l}\text { Espécie secundária tardia, decídua. Ocorre desde as matas do interior do Rio Grande do } \\
\text { Sul até Minas Gerais. Espécie atualmente ameaçada de extinção segundo a Lista } \\
\text { Vermelha de espécies ameaçadas (IUCN), devido a sua madeira ser utilizada na } \\
\text { confecção de móveis finos e molduras. }\end{array}$ \\
\hline $\begin{array}{l}\text { 11. Ficus } \\
\text { benjamina } \\
\text { (figueira- } \\
\text { benjamina) }\end{array}$ & $\begin{array}{l}\text { Esta espécie destaca-se devido a sua biologia reprodutiva, originária da Ásia, suas flores } \\
\text { concentram-se no interior do figo, sendo polinizadas por uma vespa. No entanto, esta } \\
\text { espécie de vespa polinizadora não existe no Brasil, assim, esta figueira não se reproduz } \\
\text { por sementes neste país. Existem ainda espécies de figueiras em que a vespa } \\
\text { polinizadora de suas flores foram extintas globalmente (Ficus elastica), neste caso, essa } \\
\text { espécie reproduz-se só assexuadamente, sendo o homem o único animal capaz de } \\
\text { promover a sua reprodução, replantando seus ramos em novas áreas. }\end{array}$ \\
\hline $\begin{array}{l}\text { 12. Myrciaria } \\
\text { cauliflora } \\
\text { (jaboticaba) }\end{array}$ & $\begin{array}{l}\text { Árvore frutífera ocorrente em florestas estacionais semidecíduas do Brasil, sua fruta é } \\
\text { consumida ao natural ou em geleia. A casca é útil contra irritações da pele. As flores são } \\
\text { brancas, pequenas, florescem diretamente no caule e ramos (caulifloria). Fruto baga, de } \\
\text { casca preta com polpa branca, saborosa, com uma única semente. }\end{array}$ \\
\hline $\begin{array}{l}\text { 13. Piper } \\
\text { amalago } \\
\text { (jaborandi) }\end{array}$ & $\begin{array}{l}\text { Espécie comum em áreas que apresentam um certo grau de degradação, com flores } \\
\text { agrupadas em inflorescências em formato de espiga, diminutas e com pétalas ausentes, } \\
\text { estas são polinizadas por morcegos, que têm nos frutos deste gênero uma de suas } \\
\text { principais fontes de alimentação. }\end{array}$ \\
\hline $\begin{array}{l}\text { 14. Urera } \\
\text { baccifera } \\
\text { (urtiga) }\end{array}$ & $\begin{array}{l}\text { Espécie nativa comum em bordas de florestas, com pecíolo vináceo e folhas com margem } \\
\text { serreada, de importante identificação em trilhas interpretativas, pois é dotada de tricomas } \\
\text { urticantes que podem causar intensa dor quando tocados. }\end{array}$ \\
\hline
\end{tabular}




\section{A trilha interpretativa elaborada e o seu potencial educador ambiental}

Nesta trilha elaborada, os visitantes tem a oportunidade de caminhar juntamente com um guia, ou mesmo desenvolver uma caminhada ao longo da citada trilha de forma autoguiada, por um percurso com espécies botânicas plaqueadas, contendo informações acerca da importância ecológica, econômica e/ou socioambiental de tais espécies.

Um outro exemplo bem sucedido de trilha construída diz respeito a "Trilha do Jatobá", inserida na Estação Ecológica dos Caetetus e localizada nos municípios de Gália e Alvinlândia (SP). Na "Trilha do Jatobá", segundo Tabanez et al. (1997), incluiu-se ao longo da trilha uma abordagem de aspectos dos ecossistemas, tais como a fauna e a flora local, a biodiversidade, conceitos ecológicos, assim como de eventuais problemas provenientes da prática de caça ilegal, erosão, invasão de plantas exóticas, dentre outros temas.

Tabanez et al. (1997) avaliaram ainda a "Trilha do Cerrado", inserida na Estação Ecológica de Assis, na região Oeste do Estado de São Paulo. No percurso da "Trilha do Cerrado", tais autores evidenciaram diferentes elementos bióticos e abióticos e suas inter-relações no ecossistema local, frisando aos visitantes a importância da vegetação do cerrado, bem como da mata ciliar na proteção às nascentes e cursos d’água.

Assim, a interpretação ambiental no percurso de trilhas, a partir da diversidade biológica, cultural e/ou histórica local existente, é voltada para a promoção da sensibilização e da conscientização entre seus visitantes acerca de temáticas relacionadas ao impacto da ação antrópica no meio ambiente e com o desenvolvimento de ações e formas alternativas do homem atuar na sociedade, pautado em bases sustentáveis, visando ainda a promoção da participação efetiva dos cidadãos nas discussões e decisões relativas a questões socioambientais.

Uma proposta pioneira trazida neste estudo da "Trilha das Araucárias", consiste na caminhada de trilhas interpretativas por seus visitantes não somente acompanhados pelo guia, mas também acompanhando as informações trazidas nas placas interpretativas existentes em seu percurso.

Assim, as placas interpretativas trarão as informações brutas sobre os aspectos relevantes da biodiversidade regional ali presente, e o guia trará interpretações complementares as disponibilizadas com a leitura de tais placas interpretativas, incrementando assim a qualidade da experiência de visitação a "Trilha das Araucárias", assim como a das demais trilhas que adotem essa proposta. Espera-se assim que futuras trilhas sejam construídas e que também adotem essa associação entre trilhas interpretativas guiadas e autoguiadas.

O presente trabalho visou ainda à divulgação desta proposta, isto é, o incentivo de outras empresas hoteleiras para a construção de trilhas interpretativas guiadas e autoguiadas, tornando assim esta proposta uma 
oportunidade de agregar práticas educativas ambientais a estas empresas, assim como de ampliar suas opções de lazer.

\section{Conclusões}

O presente estudo possibilitou a criação e o acesso a uma trilha interpretativa do tipo guiada e autoguiada aos hóspedes da empresa Radio Hotel Resort \& Convention, localizada no município de Serra Negra - SP. A "Trilha das Araucárias" tem grande potencial educador ambiental, por possibilitar o conhecimento da biodiversidade regional ocorrente na área, bem como a apresentação aos seus visitantes do papel da humanidade para a conservação e restauração dessa biodiversidade remanescente. Esta trilha interpretativa irá subsidiar a implementação de futuros Programas de Educação Ambiental, visto que o percurso da citada trilha e as práticas de interpretação ambiental com as espécies botânicas ocorrentes na área possibilitam a inserção de práticas educativas ambientais ao longo da mesma.

\section{Agradecimentos}

Ao proprietário do Empreendimento Hoteleiro Radio Hotel Resort \& Convention, Ariel Cardoso Gaiolli, por permitir a implantação da trilha, o desenvolvimento do presente estudo nas suas dependências e pelo financiamento concedido. Aos professores e funcionários da Escola Superior de Agricultura "Luiz de Queiroz" da Universidade de São Paulo (Piracicaba -SP), pelo apoio logístico e pelo auxílio na identificação do material botânico. Aos hóspedes frequentadores da "Trilha das Araucárias", pela visitação e desenvolvimento das atividades de interpretação ambiental propostas ao longo da trilha.

\section{Referências}

CEPAGRI - CENTRO DE PESQUISAS METEOROLÓGICAS E CLIMÁTICAS APLICADAS A AGRICULTURA. A Classificação climática de Koeppen para o Estado de São Paulo. Universidade Estadual de Campinas (UNICAMP). 2009. Disponível em: <http://www.cpa.unicamp.br/outras-informacoes/clima-dosmunicipios-paulistas.html>. Acesso em: 11 de jan. de 2015.

ESPÍNDOLA, C.R.; GARCÍA, G.J. Interpretação fotográfica de redes de drenagem em diferentes categorias de solos, Campinas, SP. Notícia Geomorfológica, v. 18, n. 35, p. 71-94, 1978.

FIDALGO, O.; BONONI, V L.R. (Coords). Técnicas de coleta, preservação e herborização de material botânico. São Paulo: Governo do Estado de São Paulo / Secretária do Meio Ambiente / Instituto de Botânica. 1989. 62p. 
FIGUEIREDO, R.A.; MATTIAZZI, B.; KLEFASZ, A. Florestas urbanas: Novo Paradigma para o Turismo Sustentável e para a Educação Ambiental. In: CASTELLANO, E.G.; FIGUEIREDO, R.A.; CARVALHO, C.L. (Orgs.). (Eco) Turismo e Educação Ambiental: Diálogo e Prática Interdisciplinar. São Carlos: Rima, 2007, p. 219-229.

GAMBOA, I.; BARRETTO, V.C.M.; XAVIER, M.V.M. Implantação de trilha interpretativa em áreas de mata ciliar e cerrado na Universidade Estadual de Goiás, unidade universitária de Ipameri (GO). Espaço em Revista, v. 11, n. 2, p. 169-179, 2009.

GOOGLE MAPS. Mapa da vegetação do município de Serra Negra, SP. 2015. Disponível em: <https://www.google.com.br/maps/@-22.6100789,-46.6956711,5339m/data=!3m1!1e3?hl=pt-BR>. Acesso em: 31 jan. 2015.

GUIMARÃES, V.F.; MENEZES, S.O. Uso de trilha interpretativa na Educação Ambiental: uma proposta para o município de Rosário da Limeira (MG). II Fórum Ambiental da Alta Paulista. Tupã: CD-ROOM. 2006. p. 1-22.

IUCN - INTERNATIONAL UNION FOR CONSERVATION OF NATURE. The IUCN Red List of Threatened Species. Araucaria angustifolia. 2014a. Disponível em: <http://www.iucnredlist.org/details/32975/0>. Acesso em: 16 jan. 2015.

IUCN - INTERNATIONAL UNION FOR CONSERVATION OF NATURE. The IUCN Red List of Threatened Species. Cedrela fissilis. 2014b. Disponível em: $<$ http://www.iucnredlist.org/details/33928/0 >. Acesso em: 19 jan. 2015.

KÖPPEN, W. Climatologia: con un estudio de los climas de la tierra. México: Fondo de Cultura Económica, 1948. 479p.

KRONKA, F.J.N. et al. (Orgs.). Inventário florestal da vegetação natural do Estado de São Paulo. São Paulo: Imprensa Oficial, 2005. 253p.

LORENZI, H. Árvores Brasileiras: Manual de identificação e cultivo de plantas arbóreas nativas do Brasil. Nova Odessa: Instituto Plantarum, 2008. v. 1, 384p.

LOUREIRO, C.F.B. Trajetória e fundamentos da Educação Ambiental. São Paulo: Cortez, 2009. 150p.

MORAES, W.V. Ecoturismo: capacitação de profissionais. Viçosa: Aprenda Fácil, 2000. 170p. (Série Ecoturismo; v.3).

PÁDUA, S.M. Cerrado Casa Nossa: um projeto de Educação Ambiental do Jardim Botânico de Brasília. Brasília: UNICEF, 1997. 35p.

POSSAS, I.M. Programa GUNMA: integrando parque ecológico e comunidade no município de Santa Bárbara do Pará. 1999. 73f. Dissertação (Mestrado em Psicologia) - Universidade Federal do Pará, 1999.

RAMOS, V.S. et al. Árvores da floresta estacional semidecidual: guia de identificação de espécies. São Paulo: Editora da Universidade de São Paulo / Biota Fapesp, 2008. 320p. 
SILVA, D.M.; LORENCINI JÚNIOR, A. A relação entre trilhas interpretativas, Interpretação Ambiental e Educação Ambiental, e a importância das espécies arbóreas para essas atividades. Anais do II Simpósio Nacional de Ciência e Tecnologia. Universidade Tecnológica Federal do Paraná. Ponta Grossa: CDROOM (Artigo: 160). 2010.

SOARES, M.P. Verdes urbanos e rurais: orientação para a urbanização de cidades e sítios campesinos. Porto Alegre: Cinco Continentes, 1998. 242p.

SOUZA, V.C.; LORENZI, H. Botânica Sistemática: guia ilustrado para identificação das famílias de Fanerógamas nativas e exóticas no Brasil, baseado em APG II. 2ed. Nova Odessa: Instituto Plantarum, 2008. 704p.

TABANEZ, M.F. et al. Avaliação de trilhas interpretativas para Educação Ambiental. In: PÁDUA, S. M.; TABANEZ, M. F. (Orgs.). Educação Ambiental: caminhos trilhados no Brasil. Brasília: Instituto de Pesquisas Ecológicas - IPÊ, 1997. p. 89-102.

TILDEN, F. Interpreting Our Heritage. Chapel Hill: The University of North Carolina Press, 2007. 212p.

TUAN, Y.F. Topofolia: um estudo da percepção, atitudes e valores do meio ambiente. São Paulo: DIFEL, 1980. 288p.

VASCONCELLOS, J.M.O. Avaliação da visitação pública e da eficiência de diferentes tipos de trilhas interpretativas no parque estadual pico do Marumbi e reserva natural Salto Morato. 1998. 151 f. Tese (Doutorado em Ciências Florestais) - Universidade Federal do Paraná, 1998.

VASCONCELLOS, J.M.O. Educação e Interpretação Ambiental em Unidades de Conservação. Fundação o Boticário de Proteção a Natureza. Cadernos de Conservação, ano. 3, n. 4, 2006.

VELOSO, H.P. Sistema fitogeográfico. In: INSTITUTO BRASILEIRO DE GEOGRAFIA E ESTATÍSTICA - IBGE. Manual técnico da vegetação brasileira. Rio de Janeiro, 1992. p. 8-38.

VELOSO, H.P.; RANGEL-FILHO, A. L. R.; LIMA, J. C. A. Classificação da vegetação brasileira adaptada a um sistema universal. Rio de Janeiro: IBGE, 1991. 123p. 